\title{
Academic Leadership Development Programs: Conceptual Foundations, Structural and Pedagogical Components, and Operational Considerations
}

\author{
The Rutgers Leadership Academy-A Case Study \\ Brent D. Ruben \\ Rutgers University \\ Richard De Lisi \\ Rutgers University \\ Ralph A. Gigliotti \\ Rutgers University
}

\begin{abstract}
In response to both the lack of formal leadership training and the challenges facing leaders across higher education, a number of programs are being planned and initiated at colleges and universities. This application brief highlights the conceptual foundations, structural components, and operational considerations of one such program, the Rutgers Leadership Academy (RLA). RLA was created to provide an integrated leadership development program for individuals in academic, administrative, and professional programs who aspire to assume or advance in leadership positions. The program is theory-based, and emphasizes leadership, communication, and organizational concepts and competencies. Somewhat uniquely, it is designed for both academic and administrative leadership positions, and it highlights the importance of informal as well as formal leadership roles, among other core topics. We have found the proposed model to be useful in developing high-quality leadership initiatives for our institution, and the core components of the model and initial outcomes may be of use to others in their leadership development efforts.
\end{abstract}

\section{Issue Statement}

There was a time when being the best among equals, a master of one's discipline or technical area, was the primary-sometimes the sole - talent-set regarded as necessary for leadership at a college or university. Being a noted scholar and luminary in one's field was the primary qualification to be an academic leader; and superior technical knowledge and skills were the essential capabilities thought to be necessary for leadership in service or administrative areas. The problems and challenges one encountered as leaders were well-bounded, and often quite nicely addressed within the comfortable siloes of one's program, department, or discipline.

Even a cursory scan of the higher education environment reveals how dramatically this well-ordered, well-defined and conveniently-segmented world has changed, and along with it, the knowledge and skill-set required for leadership effectiveness. Being highly accomplished in 
one's own area — academic discipline or technical specialization — no longer provides an adequate foundation for effectively addressing the contemporary challenges that confront higher education (Ruben, De Lisi, \& Gigliotti, 2017).

These challenges - and also the substantial opportunities - are numerous and they come from all directions - economic realities of the marketplace, financial and career needs of students and their parents, capabilities and difficulties posed by new technologies, employer demands for a better prepared workforce, an increasing emphasis on metrics and the measurement of performance, regulatory requirements of governments, accountability pressures from boards and accreditors, and internal concerns by faculty, staff, and students as institutions respond to the rapidly changing higher education landscape. Seldom do these challenges have sources or solutions within any single department or functional area of a college or university. Rather, most transcend departmental and disciplinary boundaries and require systemic solutions - engaging perspectives of multiple internal and external stakeholders to identify, understand, and address the challenges, and to take advantage of available opportunities.

Although the challenges confronting academic and administrative leaders are daunting, few institutions or disciplines have traditionally offered or required systematic preparation in higher education leadership roles (Gigliotti, 2017; Gmelch \& Buller, 2015; Ruben, et al., 2017; Ruben, 2006). At the same time, there has been a widespread critique of the effectiveness of leadership development programs (Kellerman, 2012; Pfeffer, 2012). The need for more systematic approaches to leadership recruitment, preparation, and development is becoming increasingly apparent and a growing number of colleges, universities, associations, and consortia are devoting increasing attention to formal and informal leadership development (Gmelch \& Buller, 2015; Gmelch, Damico, \& Hopkins, 2011; Ruben, et al., 2017).

As those who have begun to initiate leadership programs are well aware, creating and implementing effective programming for faculty administrators is not an easy task. This is particularly the case at research-teaching institutions given the multiplicity of mission elements which leaders must pursue simultaneously, and where individuals are used to thinking of leadership primarily in terms of disciplinary or technical expertise. Also, contributing to the leadership challenges confronting both faculty and staff administrators in these institutions are the dynamics of loosely-coupled systems (Weick, 1976), and the diverse array of professional, administrative, technical and support personnel involved all with their own cultures, performance criteria, and incentive structures. The diverse and often conflicting views of the priority goals for the institution and its units, the traditions of collegial decision-making, and the numerous external stakeholders who often have their own unique views on the role and appropriate directions of our institutions provide further challenges. Within this context, successful and effective leadership development programming requires thoughtful planning, a well-articulated view of the nature of leadership that fits with the realities of higher education, a careful analysis of the structural and pedagogical components necessary to translate leadership theory into a coherent framework, and attention to a number of operational considerations that are critical to successfully achieving the intended outcomes. 


\section{The Rutgers Leadership Academy}

The Rutgers Leadership Academy (RLA) has been created to address this pressing need within higher education in a manner that takes account of the considerations described above, and it is the focus of this current application brief. RLA was created to provide a broad, integrated array of leadership education and development modules for faculty and staff in academic, administrative, and professional programs. The program is designed for mid-career faculty and staff who aspire to assume or advance in leadership positions. Each discipline, department, or school has particular challenges and themes that leaders must address. In addition, all leaders within higher education face common challenges endemic to the sector. Personal leadership and accountability, thoughtful planning and priority setting, effective internal communication, strong relationships with key external constituencies, collegial and collaborative relationships among faculty and staff within units, systematic approaches to planning and implementing change, and high standards and innovation in programs and services are among those dimensions critical in all organizational settings. The same can be said for attention to faculty and staff workplace climate, organizational structure and effective processes, information management, planned change, the assessment of unit and institutional effectiveness, and a focus on documenting outcomes and accomplishments.

Whether the leader in question is a department chair in history, mathematics, or family medicine, a dean of liberal arts or education, the head of a key university committee, the coordinator of a laboratory or a creative writing program, a vice president for research or external relations, or a senior administrator in an academic or administrative program, leaders face a number of the same challenges, and many, if not most, of the same fundamental knowledge and leadership competencies are needed. Substantive considerations vary from one discipline or technical area to another, but process considerations, such as clearly defining unit aspirations, effective planning, appropriate engagement of colleagues to create a shared understanding and commitment to plans and goals, and effective communication are among the cross-cutting areas critical to success by all leaders and all levels in all fields. Often, attention to process dynamics is as - if not more - critical to successful leadership outcomes, than the sheer brilliance of the idea being advanced.

Based on this assumption, the RLA program focuses on the development of cross-cutting leadership concepts, competencies, and tools that can be applied across disciplines, departments, schools, and campuses. The RLA model, summarized in this white paper, has been developed to integrate core concepts from: 1) leadership, organizational, and communication theory and practice; 2) professional and leadership development concepts and best practices; and 3) an inventory of contemporary challenges and opportunities confronting American higher education and Rutgers University, in particular. The RLA framework combines these elements to provide an interdisciplinary leadership knowledge- and competency-development program.

The need for more deliberate and systematic leadership development was recognized in the Rutgers-New Brunswick Strategic Plan, leading to the creation of the RLA. The program is offered by the Center for Organizational Leadership, a division of the Office of the Senior Vice President of Academic Affairs. In April 2017, the first cohort of 28 faculty and staff completed 
the two-year RLA program. The group included 16 mid-career faculty and 12 staff (15 men and 13 women), representing the following 28 schools and departments.

- Biomedical Engineering and Chemical and Biochemical Engineering, School of Engineering

- Cardiovascular Diseases and Hypertension, Robert Wood Johnson Medical School

- Center for American Women and Politics, Eagleton Institute

- Department of Genetics, School of Arts and Sciences

- Department of Geography, School of Arts and Sciences

- Department of Materials Science and Engineering, School of Engineering

- Department of Neuroscience and Cell Biology, Robert Wood Johnson Medical School

- Department of Obstetrics, Gynecology and Reproductive Sciences, Robert Wood Johnson Medical School

- Department of Oral and Maxillofacial Radiology, Rutgers School of Dental Medicine

- Department of Pharmacology and Toxicology, Ernest Mario School of Pharmacy

- Division of General Internal Medicine, Robert Wood Johnson Medical School

- Edward J. Bloustein School of Planning and Public Policy

- Ernest Mario School of Pharmacy

- Family Medicine and Community Health, Robert Wood Johnson Medical School

- Graduate School of Applied and Professional Psychology

- Graduate School of Education

- Human Resource Management, School of Management and Labor Relations

- Mason Gross School of the Arts Extension Division

- New Jersey Institute for Food, Nutrition and Health, School of Environmental and Biological Sciences

- Pharmacoepidemiology, Ernest Mario School of Pharmacy

- Radiation Oncology, Rutgers Cancer Institute of New Jersey

- Rutgers Cancer Institute of New Jersey

- Rutgers China Office

- Rutgers Office of Continuing Professional Education and Rutgers New Jersey Agricultural Experiment Station

- School of Arts and Sciences

- School of Communication and Information

- School of Nursing, Robert Wood Johnson Medical School

- School of Social Work

The themes that are central to the RLA program were included in a book entitled, $\underline{A}$ Guide for Leaders in Higher Education: Core Concepts, Competencies, and Tools, created specifically for the Academy, and published by Stylus Publishing in 2017. The book has also been adopted at a number of institutions around the country for use in higher education courses and leadership development initiatives, and it has been nominated for the 2017 Sue DeWine Distinguished Scholarly Book Award, sponsored by the Applied Communication Division of the National Communication Association. Finally, the RLA program was featured in the January 15, 2017 edition of the Chronicle of Higher Education and was the focus of presentations at the 2016 Leadership in Higher Education Conference in Atlanta, GA and the 2017 Annual Conference for the Network for Change and Continuous Innovation in Higher Education in Minneapolis, MN. 


\section{Conceptual Foundations and Review of Relevant Literature}

At the core of the Rutgers Leadership Academy model are a number of fundamental concepts that collectively provide the rationale and the foundation for the RLA model. These include the following themes, briefly summarized here with references for additional reading:

- Too little preparation is provided for individuals who serve higher education leadership roles. As noted earlier, a frequent assumption is that smart, well-educated individuals who are thought-leaders within their fields are naturally well suited for leadership roles, and can be expected to quickly learn to become great leaders. However, even for the most adept thought-leaders in their fields, a transition from "solo pilot" to "air traffic controller" can be both difficult and painful for the individual leader and his or her colleagues (Braun, et al., 2009; Bryman, 2007; Castle \& Schutz, 2002; Gmelch \& Buller, 2015; Ruben, et al., 2017).

- Leadership is social influence. Leadership is the theme of countless academic and professional books and articles, and programs being offered for aspiring and current leaders across a broad range of fields. There are any number of definitions of leadership. Of those, we find that thinking of leadership as a process of social influence is particularly helpfulspecific enough to direct attention to particular strategies and skills, and broad enough to embrace interdisciplinary insights from a variety of fields and to benefit from nuanced perspectives on the dynamics of social influence (Gigliotti, Ruben, \& Goldthwaite, 2017; Grint; 2010; Gmelch \& Buller, 2015; Hernandez, Eberly, Avolio, \& Johnson, 2011; Northouse, 2016; Ruben, 2012; Ruben, et al.,, 2017; Ruben \& Gigliotti, 2016, 2017; Ruben \& Stewart, 2016).

- Social influence can be planned or unplanned; intended in some instances, unintended in others. Among the nuances that are important to understanding leadership is the recognition that social influence may be planned, but can also be unplanned; and it can result from both intentional and unintentional actions and activities, all potentially important to understanding leadership outcomes (Gigliotti, et al., 2017; Ruben, et al., 2017)

- Leadership can be enacted through formal and informal roles. When scholars and professionals refer to leadership roles, they often are thinking of formal, titled positions. In addition to formal roles, typically the focus of leadership programs and scholarship, informal leadership roles also play a critical role in the dynamics of social influence - particularly within higher education institutions. Leaders benefit from an authority base when they occupy formal positions; informal leaders must rely primarily on personal and interpersonal skills. Interestingly, it is often the case that highly successful formal leaders benefit also benefit from the application of these same informal strategies in pursuing their goals. Both formal and informal leadership deserve attention when it comes to understanding and developing leadership capability (Gigliotti, et al., 2017; Pielstick, 2000; Ruben, et al., 2017).

- Leadership is co-constructed by leaders and followers. To a very great degree, leaders are created by their followers. There is no leadership without followership, and hence, meaningful engagement with followers is crucial if a leader aims to promote genuine and 
lasting influence. In some instances, a leader's influence may be quite direct often as a consequence of the authority, resources, rewards, or sanctions that are available to influence the sense-making and compliance of potential followers. In other instances, a leader's words and actions may simply serve to trigger or energize preexisting susceptibilities, tendencies, or points of view. While it may appear that a leader has been extremely effective, the "effects" may simply be the consequence of how well their message and behavior resonate with the needs, goals, and expectations of followers. In still other situations, these same leadership behaviors may have little or no impact because they do not connect with or activate the needs, susceptibilities, or aspirations of potential followers. In conceptualizing and analyzing followership dynamics in any instance, there is often a tendency to romanticize the role of leadership in planning or explaining specific outcomes, and a lack of understanding of the extent to which leadership-followership dynamics are co-constructed and the ways potential followers define the success of a leader (Gigliotti \& Ruben, 2017, 2017; Meindl \& Ehrlich, 1987; Ruben, et al., 2017; Thayer, 1968).

- Leadership and social influence are often mediated. Mediation occurs through individuals interposed between those who seek to influence and those they hope to influence. Traditionally, much of the focus of leadership-followership dynamics has been on face-toface interaction. However, there is nothing particularly new about the mediation that occurs in these interactions through writing and mass media. More recently, the availability of internet-based technologies and social media provide and encourage decentralized and distributed message initiation, and these give rise to far greater complexity in conceptualizing, analyzing, and coordinating social influence strategies (George \& Sleeth, 2000; Ruben, 2006; Ruben \& Stewart, 2016).

- Leadership is enacted through communication, through verbal, nonverbal, and material modes. Communication is the mechanism through which leadership behaviors are displayed, conveyed, received, and interpreted, and the means through which leader-follower interactions take place. Leadership is discursive in the traditional sense of spoken and written discourse, but influence can also occur as a consequence of actions, gestures, dress, facial expressions, the consequences of space and time, artifacts, and even silence - the absence of discourse (Barge \& Fairhurst, 2008; Fairhurst, 2007; Fairhurst \& Connaughton, 2014a, 2014b; Fairhurst \& Sarr, 1996; Gigliotti \& Ruben, 2017; Ruben, et al., 2017; Watzlawick, Bavelas, \& Jackson, 1967; Witherspoon, 1997).

- Communication is both a leadership tool and strategy, and a fundamental conceptual foundation for understanding the dynamics of leadership and social influence. Building upon the previous bullet point, it is through communication that the personal preferences, organizational and societal cultures, and community traditions are developed, and these have a profound role in shaping everyday communication dynamics and outcomes associated with social influence (Barge \& Fairhurst, 2008; Fairhurst, 2007; Fairhurst \& Connaughton, 2014a, 2014b; Fairhurst \& Sarr, 1996; Gigliotti \& Ruben, 2017; Ruben, et al., 2017; Ruben \& Stewart, 2016; Thayer, 1968; Witherspoon, 1997).

- Social influence dynamics are historical. Actions, reactions, and events of the moment always have a historical context - individual, relational, organizational, and institutional- 
which must be understood to fully comprehend or anticipate the significance of discourse or specific experiences that occur at a particular point in time (Ruben \& Stewart, 2016; Ruben, et al., 2017).

- Leadership and social influence roles require both vertical and horizontal competencies (i.e., knowledge and skill-sets). Vertical leadership competencies include disciplinary, technical, and position-specific education, knowledge, and skill. Horizontal competencies are cross-cutting knowledge and competencies — analytic, personal, organizational, and communication - applicable for leadership across contexts. While vertical competencies are necessary for a leader's success in most situations, horizontal competencies transcend specific settings and sectors, and are increasingly recognized as also critical for outstanding leadership in a wide variety of settings and sectors, including higher education. Traditionally, vertical competencies have been emphasized in the recruitment of leaders within higher education, whereas horizontal competencies have often been given less attention in conceptualizing the competencies needed for a particular position, including efforts at recruitment, incentivizing, development, and retention. (Markman, 2017; Ruben, 2006; Ruben, 2016, 2012; Ruben \& Fernandez, 2009; Ruben, et al., 2017)

- Within higher education institutions, successful leadership requires thoughtful collaboration among individuals from multiple levels representing diverse backgrounds and subcultures from within the organization. Colleges and universities have arrays of cultural groups that interact and intersect within a single organizational structure. These cultural groups include faculty, staff, and students, each of whom might have different priorities within the overall mission of the institution. Moreover, each group might consist of individuals that bring gender, racial, ethnic, disciplinary, experiential, and political variability, as well as their own agenda of personal concerns, priorities, training, identities, and distinctive points of connection to their department, school, and institution. This diversity within academic organizations requires effective leaders to become adept as organizational ethnographers and skilled cross-cultural communications to assess, understand, appreciate, and benefit from the cultural complexities in their work. (Braun, et al., 2009; Ruben, 2006; Ruben, et al., 2017).

- Success as a higher education administrator requires attention to both leadership and management. While often described in quite different terms, in our view, these two domains are neither wholly distinct nor mutually exclusive. Leadership functions include: creating a vision and rallying others around these shared aspirations; energizing followers to advance the organization; and planning, guiding, and implementing change. Management functions include responsibility for individual and organizational performance including oversight of budgets and accounts, projects, IT, meetings, human resources, communication, and crises and critical incidents, among other management activities. While leadership is often glamorized more than management, both sets of functions are indispensable - critical for organizational effectiveness, member satisfaction, and successful outcomes. Failure to assure alignment between management activities and leadership activities is likely to mean that neither will succeed as intended. (Kotter, 2013; Ruben \& Gigliotti, 2016, 2017; Ruben, et al, 2017). 
- Purposeful training and development programs play against a background of the natural training and development influences provided by one's reoccurring experiences in an organization. Purposeful training and development programs that are created to address specific goals are an increasingly common feature within colleges and universities. Such programs are seen as a way to promote individual and organizational change. In conceptualizing and designing these planned interventions, it is important to recognize that there are also very influential unplanned training interventions occurring 24/7 within every organization, as individuals observe and learn through the experiences and role-modeling that occurs around them. These 24/7 influences are the raw materials of socialization that occur naturally in any organization and are learned through cultural emersion and experience with various role models throughout the institution. Despite all intentions, planned interventions, such as a leadership development program, are likely to be less influential than the impact of long-term, 24/7 socialization. The challenge, where the goal is to provide more than a cosmetic and rhetorical veneer, is to conceive of and design programs that are powerful, promote reflection, reinforce guiding values, encourage the adoption of new and better practices, and most importantly find ways to reinforce new messages, models, and behaviors throughout the culture of the organization. (Gmelch \& Buller, 2015; Ruben, et al., 2017).

- Leadership excellence requires a commitment to a recursive process of goal setting, knowledge and skill development, application, and review \& debriefing. Becoming a more insightful and skilled leader is a recursive process. Individual and organizational change are, at best, incremental and require ongoing efforts to encourage leaders to establish personal leadership philosophies, to set thoughtful goals, to clarify their desired legacies, to reflect on their successes and failures, and to recognize that improving one's leadership capabilities is an iterative and continuing task. (Gmelch \& Buller, 2015; Ruben, 2006, Ruben, et al., 2017).

\section{Structural and Pedagogical Components}

Given these conceptual foundations, in thinking through the design and development of content for this academic and administrative leadership development program, we structured the curriculum to include and integrate: 1) organizational concepts; 2) leadership concepts; 3) leadership competencies; 4) an overview of the institution/campus and the landscape of higher education more broadly; 5) opportunities for participant discussion, interaction, and reflection; and 6) completion of a campus-based project with each participant taking the lead with support from a more senior campus administrator. Our approach is consistent with that of Gmelch \& Buller (2015) who emphasized the importance of cultivating conceptual understanding, skill development, and reflective practice in academic leadership development programs. Given these ambitious goals, RLA was designed as a two-year (four semester) program.

Program concepts and components include the following:

- The two-year program emphasized reading, discussion, reflection, and integration of concepts and skills. In this regard, the RLA stands in contrast to many leadership "workshops," that are much shorter in duration. The capstone projects, in particular, were completed in real-time and often took a full two semesters to implement and/or bring to completion. 
- A broad array of topics are addressed, among them: institutional structure and mission, the national and institutional challenges facing higher education, leadership theories and concepts, formal and informal leadership roles and responsibilities, finance and budgeting models and practices, law and regulation, disciplinary and institutional cultures, decisionmaking, leadership communication, the influence of multiple publics, accreditation, and leadership tools related to organizational assessment, planning, change, metrics, and selfassessment.

- Access and exposure to senior campus leaders as instructors helps to validate the program, and reinforces concepts and competencies that are critical for leadership in higher education. Senior leaders address some of the specialty topics in the program, such as budget, higher education law, or government affairs. Placing such topics in the local, Rutgers context is important for participant buy-in, learning, and reflection.

- Participation by mid-career academic and staff leaders and aspiring leaders from a range of fields/specialties/roles. There are other programs at Rutgers for current academic and administrative leaders (deans, chairs, directors, and so forth). The RLA is targeted for those who aspire to join the ranks of university leaders as well as those who aspire to advance to higher levels of leadership responsibility and authority. The mix of participants allows for rich discussions of the various sub-cultures on campus, especially differences between (tenured) faculty and staff.

- Emphasis on informal as well as formal leadership concepts and competencies. The focus on informal leadership drives home the point that leadership is about social influence and, in higher education, social influence is often divorced from positions of formal authority. This is especially true with respect to faculty roles and governance (Bowen \& Tobin, 2015; Pielstick, 2000; Ruben, et al, 2017).

- Focus on Rutgers, but also other institutions and sectors, guided by a commitment to encouraging learning from organizational and leadership best practices and role models wherever they are present (e.g., Nordstrom's standardization, predictability, and reliability of service standards and skills of staff) (Spector \& McCarthy, 2012).

- The integration of informational and experiential content (e.g., case studies, simulations, group discussions to identify and encourage learning of concepts and best practices). The RLA is composed of a suite of modules incorporating a variety of teaching-learning methodologies, including seminars, readings, experience-based activities, simulations, case studies, self-assessment inventories, and leadership roles in individual and collaborative projects.

- Offer reading materials that emphasize theory, core concepts, applied models, and current instances of relevance tailored for higher education.

- Provide experiences that equip leaders with training necessary for them to apply the skills of organizational and interpersonal ethnography — careful observation, listening, record keeping, and analysis using metrics central to higher education.

- Promote individual and organizational self-reflection and include mechanisms that supportplanning, debriefing, feedback, and continual learning across the domains of planning, change, and assessment.

- Direct experience in conceptualizing, planning, implementing, and evaluating a departmental, school, or institutional program or project. Having participants take the lead on a project they designed to improve and enhance aspects of the student, faculty, staff, or patient experience is a unique feature of the RLA. These individual projects are discussed, 
approved, facilitated and supervised by more senior campus leaders who also have a stake in successful project completion. The project component helped to "advertise" and promote RLA within the university's senior leadership team.

- Expansion (franchising) of program requires attention to foundational concepts and programmatic implications - not all programs or learning modules are equally appropriate or effective for higher education personnel.

- Attention to and adoption of best-practices elsewhere, particularly within the Big Ten Academic Alliance.

- Commitment to debriefing, evaluation, and continuous improvement. Participants were asked to evaluate each session and also provided year-end evaluations. The projects completed provide a key external source of program impact on departmental, school, or university operations.

\section{Operational Considerations}

The Center for Organizational Leadership team of Ruben, De Lisi, and Gigliotti planned the two-year program and conducted some or all of each session with the RLA Fellows. For many sessions, an outside presenter - usually a very senior faculty or administrative leader attended and led part of the meeting. These university-based speakers included the former president of the university; the campus Chancellor; the Senior Vice President for Academic Affairs; current deans; the university's CFO; and the university's federal relations officer. Outside speakers, such as the editor of a major higher education publication and the vice president of a national higher education search firm, met with the group to discuss issues in higher education leadership from their unique perspectives. In general, outside speakers had considerable experience as university leaders, represented diverse points of view, and were highly respected based on their work for the university and their formal leadership roles. Overall, the RLA staffing model conforms to the "blended model" discussed by Gmelch and Buller (2015) and depicted in Figure 1.

Based on the success of the program, RLA has become an institutionalized program and will be offered on a regular basis to mid-career faculty and staff from throughout the university.

Figure 5.1 Academic Leadership Program Staffing Continuum

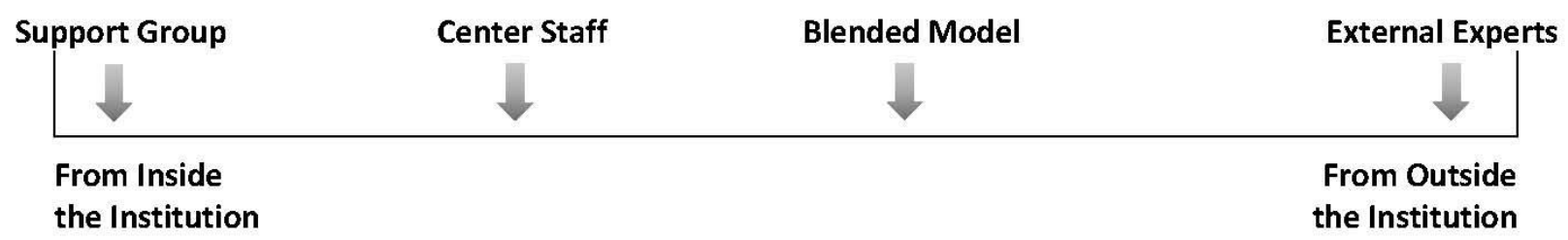

Figure 1: Gmelch \& Buller (2015) 
Funding was provided to pay for the development and provision of instructional materials, to provide food/beverage services for RLA sessions, and to cover travel expenses and a modest honorarium for presenters not employed by the university. RLA participants received no financial remuneration for their participation or to support their capstone projects. Any needed support/funding for projects - including release time - was provided by the participant's university mentor.

To be eligible for participation, nominees must have reporting lines that connect to Rutgers-New Brunswick, Rutgers Biomedical and Health Sciences, or a university-level administrator. Furthermore, nominees must have at least seven years of experience at Rutgers or elsewhere in higher education, and have aspirations and potential for furthering their expertise as leaders. A review committee representing different areas of the university reviewed the materials using our new electronic review system, and the RLA leadership team made the final selection decisions. Once admitted in the program, participants receive access to various instructional materials and receive regular communication regarding upcoming meetings, rules of engagement, and program expectations.

\section{Initial Outcomes}

As a part of our program assessment process, we conducted a pre-program questionnaire of RLA Fellows, and subsequent evaluations at the end of the first year and second year. The qualitative findings from these evaluations point to a shift in how individuals conceptualized leadership in higher education. Upon entering the program, a majority of the Fellows thought of leadership primarily in terms of management and control, and they hoped to gain additional skills in these areas as a result of being in the program. End-of-year evaluations indicated a shift to broader understandings of leadership, and an understanding of the critical role played by organizational culture, visioning, and planning, in addition to traditional management functions. Fellows also indicated a greater appreciation for the importance of strategic communication in both managing and leading as faculty and staff and an increase in knowledge base of contemporary higher education leadership challenges.

When asked to rate the quality of the program, all but two respondents rated the program as a "4" or " 5 ," with 5 representing an "outstanding program." A majority of survey respondents also indicated that the RLA program provided the knowledge and skills to enhance their effectiveness in their present roles. They also indicated that their participation in the program had a strong positive influence on their motivation to engage in future leadership roles. Finally, Fellows indicated a higher degree of preparedness to serve in new leadership roles at Rutgers or elsewhere in higher education.

\section{Reflections and Recommendations}

In order to keep pace with the rapidly changing landscape in higher education, institutions are well advised to become more mindful and intentional about leadership recruitment and selection. Although the highest levels of leadership are typically selected via external, national searches, the vast majority of formal leadership positions are filled by faculty and staff members already in residence at the institution. Given this reality, institutions can 
receive a significant return on investment by creating their own leadership development programs. By creating and supporting programs such as RLA, the institution signals that it values effective leadership and creates dialogue and discussion around leadership issues. Creating a "leadership culture" within the larger institutional landscape may be more important than any single leadership development program. Creation of such a culture requires resources (financial and time investment) from the highest levels of the college or university that are sustained over time.

The RLA is a good example of what it takes to begin to transform a large institution into one that has the development of leadership excellence among its strategic and operational priorities. We have found this model to be useful in developing new leadership initiatives for the University, such as the Academic Leadership Program for Rutgers Biomedical and Health Sciences (RBHS), and we hope the model is of use to others in their leadership development efforts.

\section{References}

Barge, J. K. \& Fairhurst, G. (2008). Living leadership: A systemic constructionist approach. The Leadership Quarterly, 4(3), 227-251.

Bowen, W. \& Tobin, E. (2015). Locus of authority: The evolution of faculty roles in the governance of higher education. Princeton, NJ: Princeton University Press.

Braun, S., Nazlic, T., Weisweiler, S., Pawlowska, B., Peus, C., \& Frey, D. (2009). Effective leadership development in higher education: Individual and group level approaches. Journal of Leadership Education, 8(1), 195-206.

Bryman, A. (2007). Effective leadership in higher education: A literature review. Studies in Higher Education, 32(6), 693-710.

Castle, J. B., \& Schutz, A. (2002). Voices at the top: Learning from full professors. Canadian Journal of University Continuing Education, 28(1), 79-101.

Fairhurst, G. T. (2007). Discursive leadership: In conversation with leadership psychology. Thousand Oaks, CA: Sage.

Fairhurst, G. T. \& Connaughton, S. L. (2014a). Leadership: A communicative perspective. Leadership, 10(7), 7-35.

Fairhurst, G. T. \& Connaughton, S. L. (2014b). Leadership communication. In L. L. Putnam \& D. K. Mumby (Eds.), The SAGE handbook of organizational communication: Advances in theory, research, and method, pp. 401-423. Thousand Oaks, CA: Sage. 
Fairhurst, G. T. \& Sarr, R. (1996). The art of framing: Managing the language of leadership. San Francisco, CA: Jossey-Bass.

George, G. \& Sleeth, R. G. (2000). Leadership in computer-mediated communication: Implications and research directions. Journal of Business and Psychology, 15(2), 287310.

Gigliotti, R. A. (2017). An exploratory study of academic leadership education within the Association of American Universities. Journal of Applied Research in Higher Education, 9(2), 196-210.

Gigliotti, R. A. \& Ruben, B. D. (2017). Preparing higher education leaders: A conceptual, strategic, and operational approach. Journal of Leadership Education, 16(1), 96-114. Gigliotti, R. A., Ruben, B. D., \& Goldthwaite, C. (2017) Leadership: Communication and social influence in personal and professional settings. Dubuque, IA: Kendall-Hunt.

Gmelch, W. H. \& Buller, J. L. (2015). Building academic leadership capacity: A guide to best practices. San Francisco: Jossey-Bass.

Gmelch, W. H., Hopkins, D., \& Damico, S. B. (2011). Seasons of a dean's life: Understanding the role and building leadership capacity. Sterling, VA: Stylus Publishing.

Grint, K. (2010). Leadership: A very short introduction. Oxford: Oxford University Press.

Hernandez, M., Eberly, M. B., Avolio, B. J., \& Johnson, M. D. (2011). The loci and mechanisms of leadership: Exploring a more comprehensive view of leadership theory. The Leadership Quarterly, 22(6), 1165-1185.

Kellerman, B. (2012). The end of leadership. New York: HarperCollins Publishers.

Kotter, J. P. (2013). Management is (still) not leadership. Harvard Business Review. Retrieved November 30, 2017 from https://hbr.org/2013/01/management-is-still-not-leadership

Markman, A. (2017, November 15). Can you be a great leader without technical expertise? Harvard Business Review. Retrieved November 30, 2017 from https://hbr.org/2017/11/can-you-be-a-great-leader-without-technical-expertise

Meindl, J. R. \& Ehrlich, S. B. (1987). The romance of leadership and the evaluation of organizational performance. The Academy of Management Journal, 30(1), 91-109.

Northouse, P. G. (2016). Leadership: Theory and practice. (7th ed.). Thousand Oaks, CA: Sage

Pfeffer, J. (2015). Leadership BS: Fixing workplaces and careers one truth at a time. New York: HarperCollins Publishers. 
Pielstick, C. D. (2000). Formal vs. informal leading: A comparative analysis. Journal of Leadership \& Organizational Studies, 7(3), 99-114.

Ruben, B. D. (2006). Departmental effectiveness: What is it? Why is it important? How can it be achieved. Effective Practices in Academic Leadership, 1(2).

Ruben, B. D. (2012). What leaders need to know and do: A leadership competencies scorecard (2nd ed.). Washington, DC: National Association of College and University Business Officers.

Ruben, B. D. (2016). Excellence in higher education Guide: a framework for the design, assessment, and continuing improvement of institutions, departments, and programs. Sterling, VA: Stylus Publishing.

Ruben, B. D., De Lisi, R., \& Gigliotti, R. A. (2017). A guide for leaders in higher education: Core concepts, competencies, and tools. Sterling, VA: Stylus Publishing.

Ruben, B. D., \& Fernandez, V. (Winter 2012-2013). What is leadership? The Higher Education Workplace, 4(3), 36-40.

Ruben, B. D. \& Gigliotti, R. A. (2016). Leadership as social influence: An expanded view of leadership communication theory and practice. Journal of Leadership and Organizational Studies, 23(4), 467-479.

Ruben, B. D., \& Gigliotti, R. A. (2017). Communication: Sine Qua Non of Organizational Leadership Theory and Practice. International Journal of Business Communication, 54(1), 12-30.

Ruben, B. D. \& Stewart, L. P. (2016). Communication and human behavior (6th ed). Dubuque, IA: Kendall Hunt.

Spector, R. \& McCarthy, D. P. (1995). The Nordstrom way to customer service excellence: The handbook for becoming the "Nordstrom" of your industry. Hoboken, NJ: Wiley.

Thayer, L. (1968). Communication and communication systems. Homewood, IL: Richard D. Irwin.

Watzlawick, P., Bavelas, J. \& Jackson, D. (1967). Pragmatics of human communication: A study of interactional patterns, pathologies, and paradoxes. New York: Norton.

Weick, K. E. (1976). Educational organizations as loosely coupled systems. Administrative Science Quarterly, 21, 1-19.

Witherspoon, P. D. (1997). Communicating leadership: An organizational perspective. Boston: Allyn \& Bacon. 